\title{
Editorial
}

Nephrology

\section{The Tyranny of Generic Immunosuppressants}

\author{
Bharath Ravichandran ${ }^{a} \quad$ Matthew R. Weir ${ }^{b}$ \\ ${ }^{a}$ Department of Pharmacy, University of Maryland Medical Center, ${ }^{b}$ Division of Nephrology, Department of Medicine, \\ University of Maryland School of Medicine, Baltimore, Md., USA
}

In this issue of the Journal, 2 important articles $[1,2]$ add to the growing concern of the intrusion of generic immunosuppression medications into clinical transplantation practice. On the one hand, from a financial standpoint, generics will help control costs; on the other hand, they do create important clinical concerns, especially with pharmacy substitution unbeknown to the patient or physician. The meaningful review of Tsipotis et al. [1] efficiently outlines a meta-analysis of trials examining the bioavailability of generic versus branded immunosuppressive drugs. Al Dhaybi and Bakris [2] describe an interesting case report of new onset hypertension linked to a generic cyclosporine substitution in kidney transplant recipients.

In an age where healthcare expenditures are increasingly scrutinized, the importance of maintaining the highest level of care cannot be understated. The increasing costs of medications have forced third-party payers to restrict coverage of medications as a cost containment strategy. Additionally, the costs for developing new and novel medications are highly exorbitant, forcing pharmaceutical companies to charge high prices for brand name medications to protect future investments. Because of this changing environment, most transplant centers have been forced to use generic alternatives, which now account for more than $70 \%$ of the immunosuppressant market share [3].

While reports of adverse events of generic immunosuppressants are uncommon and inconsistent, there are several characteristics of immunosuppressant medications that have led to concerns in the field of generic substitution. Given the narrow therapeutic index and complex pharmacokinetics of calcineurin-inhibitors and mammalian target of Rapamycin inhibitors, many practitioners fear that product conversion may increase the risk of adverse events. Additionally, there is significant inter- and intrapatient variability of many transplant medications; some of these factors include patient demographics, liver function, gastrointestinal disturbances, and comorbidities, as well as drug-drug, drug-disease, and drug-food interactions. These factors contribute to significant variability of many immunosuppressant medications even when using the same product. Therapeutic drug monitoring, early and often, is essential to maximize patient safety when product changes occur $[4,5]$.

Many practitioners have criticized the standards set forth by the Food and Drug Administration (FDA), which require a $90 \% \mathrm{CI}$ of the geometric mean of the generic medication to the innovator product ratio; they are therefore not stringent enough for narrow therapeutic index agents [6]. While Canada and the European Union have both adopted stricter criteria including a tighter CI range for AUC bioequivalence in certain agents, FDA standards are often misinterpreted. First, a geometric mean, unlike an arithmetic mean, is a better measure of central tendency and lessens the effect of outliers [7]. Additionally, A 12-year study by the FDA on bioequivalence data showed that under the current system of approval for ge-

\section{KARGER}

E-Mail karger@karger.com

www.karger.com/ajn
(C) 2016 S. Karger AG, Basel

0250-8095/16/0443-0204\$39.50/0
Prof. Dr. Matthew R. Weir, MD

N3W143 Nephrology, University of Maryland Medical Center

22 S. Greene Street

Baltimore, MD 21201 (USA)

E-Mail mweir@medicine.umaryland.edu 
neric medications, the average difference between the $\mathrm{C}$ and AUC between generic and innovator products was 4.35 and $3.56 \%$, respectively [8].

Given the escalating overall costs of transplantation and payer and policy limitations, increased usage of generic immunosuppressants is inevitable. Additionally, as most kidney transplant recipients lose Medicare coverage at 3 years post-transplantation in the United States, 90\% of transplant centers report having patients with difficulty affording their medications [9]. In order to maintain patient adherence to immunosuppressant therapy, many patients will be forced into choosing a cheaper generic alternative that they can afford. Patients with private insurance may be forced into product changes annually with any third-party payer formulary updates. The parameter of drug shortages is one that is outside of the control of practitioners that will force patients to switch formulations; this has been a common issue recently with generic tacrolimus formulations. Finally, generic competition often forces pharmaceutical companies to focus on newer products with patient-assistance programs, essentially forcing many patients to turn to generic alternatives when programs dissolve.

While there are concerns about the generic substitution of immunosuppressant medications impacting patient outcomes, the focal point should be redirected to identifying strategies to optimize patient adherence. Many factors surrounding generic substitution are out of the control of practitioners, as patients are often subject to the whims and fancies of payers, policies, and pharmacies. As a transplant center, focusing on the modifiable factors like patient education could provide transplant recipients and their families with the information to navigate product changes. If a patient is forced to switch immunosuppressant products for any reason, there should be a mechanism for them to contact the transplant center to notify them. In the setting of a product change, vigilance is recommended on the part of the transplant center, performing early and frequent therapeutic drug monitoring.

One additional mechanism to help capture product changes is the use of specialty pharmacies, especially those that are institutionally based. This enables the transplant center to maintain additional oversight of the products that are being dispensed to transplant recipients. Additionally, in the setting of medication shortages and insurance coverage issues, there is an opportunity for better communication to transplant providers and patients before a substitution is made, creating the ability to prospectively formulate a monitoring plan. While not all transplant centers have a dedicated specialty pharmacy, development of this service can be both a revenue-generating and patient-safety measure for the institution. It is important to note that pharmacy-steering laws prohibit providers from exerting undue pressure on their patients to fill their prescriptions at specific pharmacies, so this cannot be presented to patients as a requirement.

Finally, the rising costs in the current healthcare system force transplant centers to turn to generic immunosuppressants for many of their patients. Although there are many concerns of the consistency of generic alternatives to their innovator products, adopting a vigilant monitoring strategy when changing products mitigates the risks of variability. A critical need for better communication between pharmacies, patients, and physicians is an urgent and critical requirement. These articles highlight this concern.

\section{Disclosure Statement}

None.

\section{References}

1 Tsipotis E, Gupta NR, Raman G, Zintzaras E, Jaber BL: Bioavailability, efficacy and safety of generic immunosppressive drugs for kidney transplantation: a systemic review and metaanalysis. Am J Nephrol 2016;44:206-218.

2 Al Dhaybi O, Bakris G: New onset hypertension linked to generic cyclosporine substitution in post renal transplant patient. Am J Nephrol 2016;44:219-223.

3 Staatz CE, Tett SE: Clinical pharmacokinetics and pharmacodynamics of tacrolimus in solid organ transplantation. Clin Pharmacokinet 2004;43:623-653.
4 Alloway RR, Sadaka B, Trofe-Clark J, Wiland A, Bloom RD: A randomized pharmacokinetic study of generic tacrolimus versus reference tacrolimus in kidney transplant recipients. Am J Transplant 2012;12:2825-2831.

5 Ensor CR, Trofe-Clark J, Gabardi S, McDevitt-Potter LM, Shullo MA: Generic maintenance immunosuppression in solid organ transplant recipients. Pharmacotherapy 2011; 31:1111-1129.

6 Klintmalm GB: Immunosuppression, generic drugs and the FDA. Am J Transplant 2011;11: 1765-1766.
7 Trofe-Clark J, Gabardi S, McDevitt-Potter L, Alloway RR: Immunosuppression, generic drugs and the FDA. Am J Transplant 2012;12: 792-793; author reply 794.

8 Davit BM, Nwakama PE, Buehler GJ, et al: Comparing generic and innovator drugs: a review of 12 years of bioequivalence data from the United States food and drug administration. Ann Pharmacother 2009;43:1583-1597.

9 Evans RW, Applegate WH, Briscoe DM, et al: Cost-related immunosuppressive medication nonadherence among kidney transplant recipients. Clin J Am Soc Nephrol 2010;5:23232328.
Generic Immunosuppressive Drugs:

Cause for Concern?
Am J Nephrol 2016;44:204-205

DOI: $10.1159 / 000449022$ 